\title{
$\begin{array}{llllllll}R & E & S & \text { E } & N & H & \text { A } & S\end{array}$
}

\section{FORDLÂNDIA. ASCENSÃO E QUEDA DA CIDADE ESQUECIDA DE HENRY FORD NA SELVA}

Greg Grandin

Rio de Janeiro: Editora Rocco, 2010

Fania Fridman

Professora Associada do Instituto de Pesquisa e Planejamento Urbano e Regional da Universidade Federal do Rio de Janeiro e pesquisadora do CNPq

O livro do historiador e professor da Universidade de Nova York Greg Grandin é uma narrativa da saga da Ford Motor Company na Amazônia brasileira desde o final da década de 1920 até meados dos anos 1940. Não por acaso o autor utilizou no subtítulo as mesmas expressões de Bertolt Brecht em sua peça escrita no final da década de 1920, "Ascensão e queda da cidade de Mahagonny" - onde tudo é permitido desde que se tenha muito ouro -, e do jornalista William L. Shirer em seu livro "Ascensão e queda do Terceiro Reich" publicado em 1960 e resultado de minuciosa busca em documentos, diários, discursos, relatórios e em arquivos do regime nazista alemão. O livro de Grandin, escrito com objetividade jornalística, também faz um relato factual muito bem documentado, e vale a pena recuperar aqui os principais acontecimentos daquela epopeia na selva.

O projeto de Henry Ford de plantar seringueiras não se restringiu à busca por alternativas mais baratas para aquisição da borracha, monopolizada pelas colônias inglesas na Ásia, necessária à fabricação de pneus, mangueiras, válvulas e outros componentes de seus carros modelos T (o "Ford Bigode") e A. Este homem, por ter juntado a linha de montagem sincronizada com a produção em massa barateando os custos, era admirado por Thomas Edison, Harvey Firestone, Lênin, Trotski, Hitler, Mussolini e o muralista Diego Rivera. No Brasil, sua autobiografia My life and work foi lida por industriais, políticos e escritores, entre os quais, Monteiro Lobato, que a traduziu e prefaciou. No entanto, o antissemita e inimigo confesso dos sindicatos que disseminou o medo em suas fábricas nos Estados Unidos por meio de esquadróes armados, assumiu a missão de civilizar os povos atrasados, já que dizia estar seu país corrompido por sindicatos, políticos, judeus, advogados, militaristas e banqueiros de Wall Street, e onde isto não seria mais possível. A Fordlândia, localizada às margens do rio Tapajós, seria um núcleo modelo no qual deveriam ser mantidas as virtudes rurais $\mathrm{e}$ corrigidos os males urbanos.

Antes da Amazônia, Ford quis cultivar seringueiras na Flórida em 1924. No entanto, divulgada tal intenção, ocorreu uma grande especulação no preço da terra, ocasionando o abandono do programa. A escolha deslocou-se para o Brasil, que até o final do século XIX havia sido o maior produtor de borracha do mundo. Além disso, uma Comissão organizada pelo Departamento do Comércio do governo Hoover em 1923 já havia apontado em seu estudo a viabilidade ali de produção de látex. Em termos da concepção "um pé na agricultura e outro na indústria”, a primeira experiência da Companhia Ford se deu em Iron Mountain (Michigan) a partir de 1919, com a aquisição de grandes extensões para extração de madeira a ser utilizada nos veículos, e a edificação de uma serraria, três fábricas de peças e uma represa para fornecimento de energia elétrica. A empresa tornou-se responsável pelo saneamento, escolas, energia, pavimentação, construção de igrejas e de salas de recreação, incluindo cinemas, e a reforma dos vilarejos, que assumiam de fato funções municipais. Greg Grandin relata que a Ford criou durante os anos 20 inúmeras cidadezinhas neste "pastoralismo industrial", o modelo implantado em Fordlândia.

As terras poderiam ter sido obtidas gratuitamente, já que em 1925 o governador do estado do Pará prometia doações a quem se dispusesse cultivar seringueiras, e em 1926, o prefeito da cidade de Belém oferecia 10 milhōes de hectares no Baixo Vale do rio Tapajós. Ainda assim, no ano seguinte, a transação tornou-se uma negociata quando metade do 1,5 milhão de hectares teve de ser comprada por 125 mil dólares de Jorge Dumont Villares, e a outra metade, constituída por terras públicas, foi recebida sem ônus. A concessão foi ratificada pelo legislativo estadual em setembro de 1927, apesar das críticas dos periódicos de tendência nacionalista tanto da capital do país quanto do Pará.

Ao serem iniciadas as atividades em Fordlândia, assentada na aldeia Boa Vista, de propriedade da família Franco e vendida à empresa, os salários dos trabalhadores variavam de 25 a 50 centavos de dólar, 
enquanto nos EUA os operários da mesma companhia ganhavam os famosos "cinco dólares por dia". Em 1928 ocorreu a primeira rebeliāo, conhecida como "A Revolta de quebra-panela", originada pela comida estragada que era servida e pela implantação do sistema selfservice. No início de novembro, armados de facóes e machados, os trabalhadores invadiram e saquearam a cozinha e o depósito, além de ameaçarem os americanos. Houve um acordo entre as partes, mas este episódio, assim como notícias de suborno e de desvio de verbas, foram publicados no jornal do Partido Comunista e, a seguir, na grande imprensa carioca. As autoridades brasileiras deslocaram soldados armados para manter a ordem.

Em 1929, quando mais de um milhão de dólares já havia sido investido, o número de trabalhadores alcançou em torno de 1.000 pessoas, vindas das aldeias de nativos da região, da seca no Maranhão e no Ceará, dos remanescentes da construção da ferrovia Madeira-Mamoré e do canal do Panamá, da Jamaica, de Barbados e de Santa Lúcia. Adicionando os familiares, havia cerca 5.000 habitantes em uma Fordlândia de infraestrutura precária. O autor se refere à "favela na selva", a casas de jogos, bordéis, bares e a lojas de mantimentos, "todos imundos" à beira do rio, ao hospital que havia afundado, à serraria com problemas e ao gerador inoperante. Neste mesmo ano começou a tomar forma a cidade, com a colocação de tubulações para água e esgoto e do sistema elétrico. A serraria e a usina geradora foram concluídas, assim como o novo refeitório, o hospital, as estradas e uma ferrovia ligando a serraria aos acampamentos de derrubada de árvores. Todos os equipamentos foram trazidos da matriz norte-americana por navio.

Quanto à habitação, os trabalhadores solteiros não qualificados ainda viviam em galpóes coletivos ou nas aldeias próximas, e os casados, nos barracos à margem do Tapajós. Os melhor remunerados alojavam-se em casas de madeira com teto de palha. Os engenheiros, supervisores e os funcionários da serraria - europeus, americanos e alguns brasileiros - viviam em pequenos bangalôs ao longo da Riverside Avenue, da Hillside e da Main Street. Os funcionários americanos mais graduados moravam em casas com varandas e jardins em uma rua larga, a Palm Avenue, à sombra de mangueiras, com calçadas, hidrantes pintados de vermelho e com iluminação pública. Neste bairro, distante $2 \mathrm{~km}$ da doca, foram erguidos um clube, um hotel, uma quadra de tênis, um cinema e um campo de golfe. Perto desta "vila americana" ficavam de prontidão um rebocador e uma lancha para qualquer emergência.

E a emergência ocorreu ao final de 1930. Com os problemas se acumulando, em um dia em que foi mais demorada a entrada no refeitório, ocorreu um motim. Os trabalhadores destruíram o prédio do escritório, a usina de força, a serraria, a garagem, a estação de rádio e a recepção, cortaram as luzes, atearam fogo nas oficinas, queimaram arquivos, saquearam depósitos e quebraram caminhões, tratores e carros. Quando estavam avançando para o bairro dos americanos, estes fugiram para a lancha. $\mathrm{Na}$ manhã do dia seguinte, um destacamento militar do exército controlou a situação, e uma comissão dos trabalhadores apresentou uma lista de reivindicações que incluía: a escolha do local para as refeições dos solteiros; permissão para frequentar bares (a bebida alcoólica era proibida); criação de dormitórios mais cômodos; oferta de comida de melhor qualidade no refeitório; e suspensão do trabalho na chuva e dos exames periódicos e obrigatórios no hospital. A companhia reagiu com a demissão em massa (com poucas exceções), o fechamento de bares e bordéis e a expulsão dos moradores.

Apesar de encontrar-se à venda, Fordlândia em ruínas não encontrou compradores. A empresa reconstituiu sua força de trabalho e, em seis meses, já se encontravam admitidos 1.500 novos funcionários, que eram obrigados a carregar consigo um livreto com foto, impressão digital do polegar e prontuário policial. $\mathrm{Na}$ cidade, onde circulavam carros Ford, surgiram um centro cívico e, na rua principal, lojas como perfumaria, padaria, barbeiro, sapataria, alfaiataria, mercearias, açougue; mercados de verduras, legumes e peixes. Do plano inicial de 400 moradias, ergueram-se inicialmente cem casas de adobe com teto de palha servidas por água e eletricidade. Em 1933, já somavam 200 habitaçôes com cobertura de metal revestido de amianto e piso de concreto, extremamente quentes para o clima local. Cada família recebeu mil metros quadrados de terreno para plantar flores e verduras. A recreação para espantar o tédio, a solidão e a depressão tornou-se assunto urgente - abriram-se playgrounds para crianças, quadra de tênis, campo de golfe, e organizaram-se caçadas, times de futebol, corridas, lutas de boxe, show de variedades, leituras, festas 
de danças, concursos "para o melhor jardim", além da projeção de filmes.

Mas as seringueiras adoeceram e, apesar de várias tentativas, entre elas os enxertos, a aquisição de sementes na aldeia dos índios mundurukus assistidos pelos franciscanos e a descoberta de novos inseticidas, 202 mil ha de Fordlândia foram trocados por uma área em Belterra, distante $115 \mathrm{~km}$ rio abaixo e localizada a 48 $\mathrm{km}$ de Santarém, em 1934. Quando, no ano seguinte, as plantações encontravam-se tomadas por fungos, Fordlândia, onde já haviam sido investidos 7 milhões de dólares, tornou-se um centro de pesquisa e de viveiros para híbridos. Para continuar com o seu projeto de "arcádia industrial", Ford exigiu que Belterra fosse erguida rapidamente. Em 1936 já havia uma praça com igreja, salão de recreação, cinema ao ar livre, campo de golfe, piscina, caixa d'água, geradores de eletricidade, bangalôs para moradia, jardins e um moderno hospital. Vargas visitou-a em outubro de 1940, quando pronunciou um discurso afirmando que "se houvesse neste mundo mais homens como o sr. Ford, não seria necessária nenhuma legislação social".

Durante o período da guerra, os presidentes brasileiro e americano assinaram um tratado garantindo a venda de toda a borracha brasileira para os EUA. No entanto, àquela ocasião, os custos operacionais de Belterra e Fordlândia continuavam muito altos, apesar de estarem ali cultivadas, com sementes trazidas do Acre e do Ceilão, quase 4 milhôes de árvores do tipo hevea. Henry Ford II, o novo dirigente da empresa e neto do fundador, decidiu vendê-las ao governo brasileiro por 244.200 dólares, o montante equivalente às indenizações devidas aos trabalhadores, quando provavelmente valeriam mais de 8 milhōes de dólares (sem contar os 20 milhōes até então investidos). As plantações e benfeitorias foram entregues ao Instituto de Pesquisa Agrária do Norte (atual Embrapa) chefiado pelo progressista agrônomo Felisberto Camargo, que sugeriu a criação de cooperativas de seringueiros, ideia retomada bem depois por Chico Mendes. Hoje, as terras de Fordlândia fazem parte da Floresta Nacional do Tapajós.

Desde 1939, quando Gastão Cruls publicou um artigo na Revista Brasileira de Geografia sobre a Companhia Ford Industrial do Brasil, passando pelo romance Bandeirantes e pioneiros, de Clodomir Vianna Moog, de 1954, a saga fordista na Amazônia vem sendo abordada em inúmeros trabalhos no Brasil e no exterior.
A estes vem se somar o detalhado e valioso registro de Greg Grandin sobre aquela que Henry Ford pretendeu comunidade modelo ao retomar, a seu modo, a utopia oitocentista de união cidade e campo.

INDICAÇÕES BIBLIOGRÁFICAS SOBRE O TEMA

DEAN, W. A luta pela borracha no Brasil. Um estudo de história ecológica. São Paulo: Nobel, 1989.

COSTA, F. A. Grande capital e agricultura na Amazônia. A experiência Ford no Tapajós. Belém: Editora da Ufpa, 1993.

LOURENÇO, E. Americanos e caboclos. Encontros e desencontros em Fordlândia e Belterra. Dissertação de Mestrado em Geografia. Departamento de Geografia, Universidade de São Paulo, 1999.

VICENTINI, Y. Cidade e história da Amazônia. Tese de Doutorado. Faculdade de Arquitetura e Urbanismo, Universidade de São Paulo, 1994.

WEINSTEIN, B. A borracha na Amazônia. Expansão e decadência, 1850-1920. São Paulo: Hucitec; Edusp, 1993.

. Visões norte-americanas da Amazônia às vésperas da Guerra Fria. Revista do IEB (45), set. 2007. 